\title{
NUEVO PARADIGMA. EL RETORNO DE LA HISTORIA*
}

Carlos Barros**

Hay un proverbio que dice que no se puede, a la vez, decir misa y tocar la campana. A quienes estamos en la organización del congreso nos tienta la idea de dedicamos sólo a la resolución de problemas logísticos, para así no tener que sacar de no sé dónde tiempo para nuestra contribución personal a los debates. Por otro lado, es justo y necesario que expongamos, y en primer lugar el coordinador del Congreso, algunas claves de la estrategia de convocatoria de Historia a Debate II, así como nuestras impresiones sobre la marcha del Congreso, pasadas ya tres jomadas de exposiciones y debates, y seis meses de preparación galopante, durante los cuales pudimos constatar respuestas entusiastas - vosotros sois la prueba- y, todo hay que decirlo, "resistencias" que dan la medida de la trascendencia de nuestro trabajo.

Añadiré pues, a riesgo de -o "con la ventaja de", según se vea- no tener suficiente perspectiva, algunas conclusiones de este nuestro macro-encuentro de historiadores, si bien todavía quedan, para la tarde de hoy y la mañana del domingo, importantes mesas redondas y ponencias.

Voy a hablar primero de "historia inmediata",-de la evolución de acontecimientos a medio año del fin del siglo XX, para después

* Transcripción, revisada y ampliada por el autor, de la cuarta conferencia plenaria del II Congreso Internacional Historia a Debate dictada el sábado 17 de julio de 1999, a las 9 horas en la Sala Compostela del Palacio de Congresos de Santiago de Compostela (España).

** Universidad de Santiago de Compostela. 
120 EL TALLER DE LA HISTORIA 2

hablar de la historia inmediata que hacemos los historiadores, o sea de "historiografía inmediata", y terminar finalmente con algunas de nuestras propuestas cara el nuevo paradigma ${ }^{1}$, entendido como una serie de consensos sobre el ejercicio de la profesión, en cuya construcción, por activa o por pasiva, estamos ya participando todos ${ }^{2}$.

\section{LA HISTORIA SE ACELERA}

La última década del siglo XX está resultando cuando menos imprevista, para no variar. En 1989 cae el muro de Berlín, sorpresivamente, y se produce lo que Fukuyama llamó “el fin de la Historia", pero, en 1994, como se dijo ya en la mesa redonda sobre Chiapas, la historia recomienza para algunos ${ }^{3}$, y, lo que es más evidente, diez años después, en 1999, tiene lugar la primera guerra de la OTAN después de 50 años. Cuando parecía que, desaparecidos los bloques militares y la "guerra fría", el mundo iba a estar dirigido por la ONU, que con sus "cascos azules" habría de aseguramos un nuevo orden internacional basado en la paz, estalla, en plena Europa, por vez primera desde la II Guerra Mundial, la guerra por iniciativa de las potencias occidentales con una violencia desproporcionada. La guerra sigue siendo, pues, la continuación de la política por otros medios no sólo para los pequeños países del antiguo bloque soviético o del "Tercer Mundo", con sus conflictos internos o fronterizos, sino también para las grandes potencias del

1. Véase asimismo "Hacia un nuevo paradigma historiográfico", Memoria y civilización, Pamplona, $\mathrm{N}^{\circ}$ 2, 1999, pp. 223-242 (también en Historias, México D. F., N 42, 1999, pp. 3-16; Prohistoria, Rosario, $\mathrm{N}^{\circ} 3$, 1999, pp. 43-57).

2. "La historia que queremos", Revista de Historia “Jerónimo Zurita”, N71,1995, pp. 309345 (también en "Vers oü souhaitons nous mener l'histoire?", Rivista di Storia della Storiografia Moderna, $\mathrm{N}^{\circ} 1-3,1995$, pp. 137-148; Anales de Historia Antigua $y$ Medieval, $\mathrm{N}^{\circ}$ 30, 1997, pp. 169-199).

3. "Chiapas y la escritura de la historia", Este/Sur, № 254, San Cristóbal de las Casas, 1999 (también en Contexto \& Educaçáo, Ijuí-Brasil, N 54,1999, pp. 29-52; A trabe de ouro. Publicación gallega de pensamento crítico, Santiago de Compostela, $\mathrm{N}^{\circ} 38,1999$, pp. 233-246). 
mundo: ¿qué mejor recordatorio en el umbral del nuevo milenio de que la historia no ha terminado $?^{4}$

Hemos ido, pues, de sorpresa en sorpresa a lo largo de los años noventa, viejas y nuevas contradicciones siguen manifestándose $\mathrm{y}^{5}$ empujando la historia. Las previsiones teleológicas que siguieron a la caída de los regímenes llamados socialistas, en el Este de Europa, no se han cumplido. Obviamente la historia continúa, y bien sabemos los historiadores que difícilmente se puede "garantizar" un futuro determinado por los intereses y las mentalidades hoy dominantes, con lo cual se abren posibilidades de futuros alternativos: el futuro está abierto. Así fue en el pasado, pero no bastan las palabras de historiadores que no hemos renunciado a hablar del presente y del futuro: sólo cuando la historia inmediata confirma que la historia sigue, pueden recuperar los actores sociales la capacidad plena de pensar históricamente, velada por las actitudes presentistas que también arrastran, paradójicamente, a algunos historiadores.

La aceleración de la historia que estamos viviendo, síntoma, causa y efecto de la globalización, en todas sus vertientes, y del desarrollo de las tecnologías de la información, es característica de los períodos de transición histórica y está provocando que la sociedad demande crecientemente la historia que se escribe. La historia tira, por consiguiente, de la historia. Nuevos y viejos sujetos sociales, culturales y políticos, buscan, a las puertas del nuevo siglo, su legitimidad en la historia: etnias y Estados; ideologías y

4. La situación del mundo (sobre todo de Rusia y los "tigres asiáticos") ya había hecho reconocer fugazmente a Fukuyama, en una entrevista para el New York Times (30 de agosto de 1998), que se había equivocado en su proclamación del "fin de la historia", véase Israel Sanmartín, "El fin de la Historia" mirado hacia atrás y pensado hacia adelante, ponencia publicada en este mismo volumen de las actas.

5. La revuelta de Seattle, en noviembre de 1999, contra la Organización Mundial de Comercio, es una muestra de las nuevas contradicciones y de su carácter global, con la diferencia, respecto de Chiapas o Kosovo, de que se trata de un hecho histórico que tiene lugar en el corazón del "Imperio", con un componente mayoritario de sindicalistas y jóvenes norteamericanos entre los participantes. 


\section{EL TALLER DE LA HISTORIA 2}

religiones; movimientos sociales y movimientos nacionalistas; lo local y lo regional, lo nacional y lo mundial. La rapidez del proceso de globalización recién iniciado genera tendencias confusas cuya plena comprensión resulta inverosímil sin considerar el factor tiempo, sin relacionar pasado, presente y futuro.

Los veloces cambios, de 1989 en adelante ${ }^{6}$, nos compelen por lo tanto a saber de dónde venimos, para mejor comprender quiénes somos y, sobre todo, adonde vamos. El siglo que viene no va a ser, desde luego, el 1984 de Orwell: va a necesitar, probablemente tanto o más que el siglo $\mathrm{XX}$, de la historia, de las ciencias sociales $\mathrm{y}$ de las humanidades ${ }^{7}$. Conforme la globalización avanza revuelve todo en todos los ámbitos (sociedad, política, cultura, mentalidades), desestructurando las identidades de las comunidades étniconacionales y de los grupos sociales a todos los niveles, así como sus relaciones con la economía, el Estado..., en suma, con la historia. Proceso de rupturas y recomposiciones en el espacio y en el tiempo que, sin duda, se va a desarrollar a una velocidad aún mayor a lo largo del siglo que comienza. En esta tesitura, ¿cuál es la responsabilidad y el papel de la historia?

De momento, los grandes beneficiarios de la creciente demanda social de historia en este cambio de siglo no parecen ser los historiadores sino los novelistas y, a distancia, los periodistas. El auge generalizado de la novela histórica ${ }^{8}$ que afecta a todas y a cada una de las épocas históricas ${ }^{9}$ es evidente en todos los países y

6. Los hechos de 1989 parecían señalar un punto de llegada (el término del siglo XX y sus "extremos") y resulta más bien que son el punto de partida de un nuevo proceso cuyo final es difícil entrever, salvo que abracemos de nuevo un "gran relato" finalista.

7. El "debate de las humanidades" iniciado en España hace dos años, supone un avance de los problemas de la enseñanza, la cultura y la sociedad del nuevo siglo.

8. Tema de una sincera discusión pos-congresual en la lista de correo electrónico de Historia a Debate durante los meses de febrero y marzo de 2000 (véanse los mensajes en www.h-debate.com).

9. El interés de los lectores de ficción por la historia de la Antigüedad, la Edad Media o el Antiguo Régimen viene a compensar la tendencia contemporaneísta- presentista de 
CARLOS BARROS 123

continentes ${ }^{10}$. En cierto grado, la crisis social de la historia es causa y consecuencia de la "ocupación" por parte de escritores, y otros no profesionales de la historia, del espacio que "corresponde" a los historiadores como intermediarios "oficiales" entre el pasado, el presente y el futuro ${ }^{11}$. "Ocupación" que para nada soluciona el problema de fondo, más bien lo agrava: la relación de los ciudadanos de la aldea global con la historia no puede basarse en la ficción ${ }^{12}$, en la invención de los hechos pasados, a riesgo de dejar el terreno libre a la manipulación política de la historia y, por ende, al totalitarismo.

La historia hecha con rigor es más necesaria, pero también más posible que nunca, porque es precisamente ahora cuando se acepta de un modo más natural la influencia del observador sobre su objeto, del historiador sobre el tema de su investigación, de la comunidad de especialistas sobre lo que es o no verdad científica. Es ahora cuando la historia puede revalidar mejor su concepto de ciencia $^{13}$, de acuerdo con las actuales ciencias de la naturaleza y de la sociedad, que ciertamente no eluden su responsabilidad hacia el presente y el futuro.

parte influyente de la historia académica y de los mass media, con el déficit de conciencia histórica que ello entraña.

10. ¿No es acaso la novela histórica el género literario que predomina par tout entre los escritores de ficción hoy en día?

11. Un índice evidente de las dificultades de los historiadores para situarse ante la actual crisis de la historia es la aseveración presentista de que el futuro nada tiene que ver con nosotros porque no somos "profetas", como si el fluir el tiempo se paralizara en el presente, que incluso para algunos tampoco debe inquietamos como historiadores, en el afán de reducimos al papel de eruditos-anticuarios.

12. Y menos todavía la de los viejos Estados y nacionalidades que resurgen con la globalización, salvo que no hayamos aprendido nada de la historia.

13. Siete décadas después del principio de incertidumbre que le dio, en 1932, a Heisenberg el premio Nobel, pervive de manera increíble entre los historiadores el concepto mecanicista y objetivista de ciencia del siglo XVII, popularizado en el siglo XIX por los historiadores positivistas; véase al respecto la tesis 3 de "La historia que viene", Historia a Debate I, Santiago, 1995, pp. 99-100 (asimismo en Secuencia, $\mathrm{N}^{\circ} 31$, México, enero-abril de 1995; Debates Americanos, $\mathrm{N}^{\circ} 2$, La Habana, julio-diciembre 1996; Storia della Storiografia, $\mathrm{N}^{\circ}$ 30, 1996; Prohistoria, Rosario, $\mathrm{N}^{\circ} 1,1997$; Cahiers du Centre de Recherches Historiques, Paris, $\mathrm{N}^{\circ} 22$, avril 1999). 
124 EL TALLER DE LA HISTORIA 2

\section{GIRO POSITIVISTA}

Frente a la crisis de los grandes paradigmas del siglo XX, y las presiones del público lector, las editoriales y los medios de comunicación social, en favor de la novela histórica, y de literatos, teóricos de la literatura y filósofos, que al equiparar historia con ficción pretenden devolver la historia profesional a su prehistoria ${ }^{14}$, ¿cómo estamos reaccionamos los historiadores profesionales?

Una parte de la comunidad internacional de historiadores, excelentemente representada en este congreso ${ }^{15}$, combina la reflexión y el debate sobre la metodología, la historiografía y la teoría de la historia con los trabajos empíricos, la academia con la utilidad social de nuestra disciplina, procura mancomunada y explícitamente incidir en la construcción del nuevo paradigma de la historia $^{16}$, sin creerse por ello en la posesión de ninguna llave mágica o verdad absoluta.

Otros colegas, sin embargo, creen hallar las respuestas a las incertidumbres del presente historiográfico en la "seguridad" de los archivos, las fuentes y la crítica de fuentes ${ }^{17}$, y en el trabajo

14. Sobra decir que no se trata de una "ofensiva" desinteresada de la literatura contra la historia, sino de un episodio más de la perenne lucha interdisciplinar por el conocimiento, la academia y el público lector.

15. En el temario del XIX Congreso Internacional de Ciencias Históricas, que se va a celebrar en Oslo en agosto de 2000, están asimismo representadas inquietudes y reflexiones (historia global, pasado y presente, pasado y futuro, balances historiográficos) que buscan como nosotros remozadas síntesis historiográficas; véanse el Bulletin dInformation de $1998\left(\mathrm{~N}^{\circ} 24\right)$ y de 1999-2000 ( $\left.\mathrm{N}^{\circ} 25-26\right)$.

16. Insistimos en que, contra el concepto vulgar y con frecuencia interesado de para digma como modelo de "obligado" cumplimiento, nosotros empleamos la acepción kuhniana de conjunto de valores y creencias compartidos por una comunidad de especialistas, "El paradigma común de los historiadores del siglo XX", La formación del historiador, Michoacán (México), $\mathrm{N}^{\circ}$ 14, 1994-95; Estudios Sociales, Santa Fe (Argentina), $\mathrm{N}^{\circ}$ 10,1996; Medievalismo, Madrid, $\mathrm{N}^{\circ}$ 7, 1997; Mentalities/Mentalités, Hamilton (New Zelande), $\mathrm{N}^{\circ}$ 1, vol. 14, 1999.

17. No nos referimos, obviamente, al necesario uso de fuentes en las investigaciones históricas, sino a quienes, haciendo tabla rasa de la evolución historiográfica en el siglo $\mathrm{XX}$, quieren restringir, consciente o inconscientemente, el oficio de historiador a sus fuentes. 
individual ajeno a cualquier grupo, "escuela" o tendencia historiográfica, salvo a la que hace más de 100 años proclamó que la función del historiador era reconstruir el pasado "tal como fue" 18 . En algunos casos, se trata de una actitud atentista, de "espera" a que se aclare el panorama historiográfico, por parte del sector de la profesión más enfrascado en los debates y la experimentación, sin caer en cuenta de que nuestra práctica, la de todos y cada uno de nosotros, está decidiendo también, por omisión, la escritura de la historia. Evidentemente, la mera "vuelta a los archivos" es un fruto circunstancial de la crisis, sin ningún sentido como alternativa historiográfica de futuro. Tendría que volver la sociedad, la cultura y la política del siglo XIX para que la escritura de la historia retrocediese, como se pretende aunque no se diga, al siglo XIX. Pero no debemos subestimar este "giro tradicional" porque puede, se quiera o no, dificultar o desvirtuar la oportunidad de un salto adelante de la historia como conclusión final de la transición historiográfica siglo XX/siglo XXI. No olvidemos que en el siglo XX los fracasos más sonados de los "nuevos historiadores" de factura annaliste, marxista y neopositivista, fueron debidos a la infravaloración del peso de los postulados negativos de la tradición positivista decimonónica en las comunidades de historiadores, empezando por sus propias filas.

¿Cómo se llegó a esta tendencia minoritaria pero en aumento, si no logramos frenarla, del "gran retomo"? Primero fueron los retornos de los temas historiográficos tradicionales, principalmente biografía e historia política, sobre lo cual ya habló Jacques Le Goff en el I Congreso Historia a Debate, apostando teórica y prácticamente ${ }^{19}$ por la reformulación de éstos, y otros géneros clásicos, con enfoques de las nuevas historias; síntesis vieja/nueva historia para avanzar que ahora, en nuestra opinión, habría que extender a

18. Uno de los aspectos positivos del "retomo a Ranke" que estamos viviendo - junto con la rehabilitación en marcha de Langlois y Seignobos - es que conocemos más y mejor a Ranke: se dice, y con razón, que no era tan simplista y objetivista como se deduce de la frase "la historia es conocer el pasado tal como fue", pero la realidad es que fue así como se difundió su magisterio entre los historiadores del siglo XX.

19. Jacques Le Goff, Saint Louis, París, 1996. 
126 EL TALLER DE LA HISTORIA 2

la historia narrativa. Sin embargo, el cambio de los temas económico-sociales de investigación por los "grandes hombres" y los acontecimientos políticos y militares que han protagonizado, ha seguido progresando, raramente con un enfoque metodológico renovado: el tema tradicional arrastra consigo a la vieja metodología "historizante", especialmente en el caso de la historia biográfica, haciendo momentáneamente realidad el fatalismo —que no compartimos $^{20}$ - de historiadores que afirman taxativamente que los objetos de investigación de la vieja historia son inseparables del positivismo y del conservadurismo ideológico correspondientes ${ }^{21}$. Falta decir, y no se suele decir, que ello ha sido así hasta ahora porque no hemos sido capaces de desarrollar más un relato histórico o una historia biográfica desde posiciones metodológicas avanzadas $^{22}$ : estamos a tiempo.

La segunda fase del retomo de lo que algunos seguimos llamando "vieja historia" es, por lo tanto, más de tipo epistemológico: se sustituyen las certezas complejas de los años 60 y 70 por la antigua creencia en las fuentes y su crítica como fundamento principal, y prácticamente único, del oficio del historiador. Reflujo historiográfico que nos aleja de las demandas culturales que, decíamos antes, la nueva sociedad nos impone. La demanda de héroes y mitos históricos a la vieja usanza - muy cultivada por regímenes totalitarios e ideologías fundamentalistas - es minoritaria entre el público culto. Tampoco es suficiente proporcionar datos y datas, nombres y hechos desnudos, hay que pre y re-elaborar la información documental con seriedad a la altura de la formación cultural y de las exigencias del lector medio a finales del siglo XX, muy distinto del lector romántico de historia escrita en el siglo XIX ${ }^{23}$.

20. Véase la tesis 8 de La historia que viene.

21. Tal como nosotros empleamos el término, no siempre coincide el conservadurismo político con el conservadurismo historiográfico.

22. Un ejemplo en sentido contrario: la nueva historia política.

23. La propia novela histórica que triunfa hoy no es del tipo Walter Scott sino que tiende a introducir a su manera temas de mentalidades, sociedad y poder, que remiten a la renovación historiográfica del siglo $\mathrm{XX}$. 
El "gran retomo" a la historia tradicional, con sus temas, métodos y teorías, toca fondo con el siglo que se acaba y empieza a generar debates y respuestas puntuales ${ }^{24}$, que nosotros queremos impulsar todavía más. Tenemos la esperanza de que haciendo visible desde la plataforma Historia a Debate la involución historiográfica en ciernes se puedan conjurar mejor los peligros que denunciamos. Este "giro positivista" no siempre está en la intención individual - no se trata de un movimiento organizado- de muchos de sus protagonistas, a quienes planteamos lo siguiente: ¿por qué no volvemos, puesto que de "retornos" se trata, a la definición del oficio que hace Jacques Le Goff en el prefacio de Tiempo, trabajo y cultura en el Occidente medieval (1978): "La historia se hace con documentos y con ideas, con fuentes y con imaginación" ${ }^{\text {"25 }}$ ? La historia seguramente nos lo agradecería, y seríamos más coherentes con nuestra propia trayectoria historiográfica, pero en realidad tampoco sería suficiente porque el retomo que necesita la historia es el "retomo al futuro", aunque sea dando un paso atrás para dar luego dos pasos adelante...

El "giro positivista" en marcha también se refleja, por omisión, en nuestro II Congreso. La premura en su organización benefició la puesta en evidencia de esta tendencia reciente que hemos seguido más de cerca en la historiografía española, pero que se manifiesta asimismo en la historiografía francesa, vinculada históricamente a Annales ${ }^{26}$,

24. Así la reacción pública de historiadores españoles contra el informe de la Real Academia de la Historia española (junio 2000), por lo que tiene de retomo positivista a una historia de España de grandes hombres y grandes batallas, impuesta por la dictadura de Franco en las escuelas y propia asimismo, desde la ideología contraria, de la historiografía liberal anterior a 1936.

25. Jacques Le Goff, Tiempo, trabajo y cultura en el Occidente Medieval, Madrid, 1983, p. 7.

26. La muerte accidental de Bernard Lepetit, en 1996, aceleró el fin del toumant critique lanzado por la revista Annales en diciembre de 1989, que nosotros saludamos en su momento con entusiasmo, y que se ha saldado, diez años después, en una disgregación y pérdida de impulso que han dado paso, últimamente, a un tournant conservateur que esperamos sea temporal, por afección a la gran escuela historiográfica fundada por Marc Bloch y Lucien Febvre, y continuada por Femand Braudel y Jacques Le Goff hasta los años 80 . 
y sin duda en otros lugares ${ }^{27}$. Hemos comentado en el comité de organización del Congreso cómo algunos colegas - y amigosespañoles que, en el año 1993, estaban bien dispuestos al debate, a la reflexión, al "combate" por la historia ${ }^{28}$, están ahora desinteresados de los problemas de la disciplina, y si mantienen una actividad individual investigadora suele ser de tonos cada vez más clásicos, menos críticos. Paralelamente hemos detectado, respecto del I Congreso, un claro rejuvenecimiento de los ponentes, sobre todo españoles $^{29}$. Con todo, este inevitable relevo generacional, que se manifestará aún más claramente en 2004, no soluciona automáticamente el problema que le puede crear a nuestra disciplina el "giro positivista": parte de los jóvenes historiadores son hoy también conservadores historiográficamente y no tienen la ventaja de haber pasado, como la generación del 68, por una etapa innovadora en los métodos y los compromisos de la historia. Por lo que sigue siendo imprescindible, mientras la biología lo permita, el papel impulsor de una parte de la generación que ha protagonizado la revolución historiográfica de la segunda mitad del siglo XX y que mantiene todavía viva la ilusión por la historia y su escritura colectiva. En cualquier caso, insistimos, el binomio joven/viejo ya no sirve tanto, como en los años 60 y 70, para definir lo joven y lo viejo de los enfoques historiográficos: la línea divisoria del debate historiográfico no es hoy tan generacional, aunque los jóvenes están en mejores condiciones objetivas ${ }^{30}$ para captar los nuevos problemas y soluciones.

27. Animamos al lector a lanzar una mirada crítica a su alrededor, y a unirse a nosotros en la crítica constructiva de este inquietante movimiento "retro" de nuestras historiografías.

28. Debate, reflexión y reivindicación que están en las antípodas de la definición del historiador que ha hecho el positivismo decimonónico; nos parece por eso inexacto denominar "neopositivista" al actual "giro tradicional" porque el neopositivismo historiográfico de la segunda mitad del siglo XX aceptó, en cierta forma, el papel activo y reflexivo del historiador antes sus fuentes.

29. La participación española es algo superior al $30 \%$ entre los ponentes, y mayori- taria lógicamente en el conjunto de inscritos al congreso.

30. Y no pocos en condiciones subjetivas: la mayoría de los participantes en las actividades presenciales y digitales de HaD son jóvenes. 
Tenemos que reconocer que el giro positivista y conservador de una parte de los historiadores antaño renovadores, el renacer de otros anteriores a la renovación historiográfica del siglo XX y la salida de las facultades de grupos de jóvenes con una concepción de la historia conservadora ${ }^{31}$, es una reacción elemental y saludable al posmodemismo y sus excesos negadores de toda objetividad histórica. Claro que, finalmente, el remedio puede ser peor que enfermedad. La tendencia insaciable de perseguir en un pasado historiográfico — cada vez más lejano - las respuestas a las crisis actuales de la nueva historia, y de las ciencias sociales, nos lleva al típico fenómeno de la convergencia de los extremos. El posmodemismo remata por igualar historia y ficción, es decir, la historia tal como era, pura literatura, antes de su homologación académica; etapa prehistórica a la cual se llega, asimismo, por la vía de indagar "hacia atrás" las raíces de nuestra disciplina: el "giro positivista" en su acepción más consecuente —narrativistase encuentra así con el "giro lingüístico" en su lectura más radical $^{32}$. Nuestra apuesta es cambiar la "marcha atrás" por la "marcha adelante" de la historiografía, recapitular ciertamente la historia y la prehistoria de la historiografía, porque es la hora de los balances, pero sin dejarse llevar alegremente por la coyuntura, sin hacer tabla rasa del siglo XX y sus corrientes historiográficas; en resumen, sin extremismos, con espíritu de síntesis, renovación y racionalidad historiográfica.

Lawrence Stone anunció, como es sabido, en $1979^{33}$ la vuelta de la historia narrativa, y en realidad se anticipó veinte años, porque es ahora, en 1999, cuando estamos viviendo el verdadero retomo de la historia-relato con la justificación teórica correspon-

31. No tanto por la enseñanza directa de profesores conservadores como por el escepticismo de muchos profesores progresistas.

32. Conocemos colegas inquietos, inteligentes y perplejos que, entre el I y II Congreso $\mathrm{HaD}$, han transitado del posmodemismo militante sin solución de continuidad a la rehabilitación de los clásicos del siglo XIX.

33. "The Revival of Narrative: Reflections on a New Oíd History", Past and Present, $\mathrm{N}^{\circ}$ $85,1979$. 


\section{EL TALLER DE LA HISTORIA 2}

diente. El debate historia/narratividad es una de las novedades de este congreso, en tres de las cinco conferencias plenarias se trata del tema ${ }^{34}$, que afecta tanto a la teoría (epistemología) como a la práctica de la historia. La novedad del fenómeno, que vendría a ser la tercera $-\mathrm{y}$ última ${ }^{35}$ - fase del retomo de la vieja historia, consiste en que los narrativistas no sólo cuestionan las aportaciones de las vanguardias historiográficas del siglo XX, lo que hace otra mucha gente, sino también las bases fundacionales del positivismo, que preconizó una historia-relato pero como historia-ciencia, sin inventar los datos. La demolición de la historia científica, en todas sus versiones, es ahora demandada por literatos y filósofos, a los cuales se han unido historiadores posmodemos, propugnando que la historia ha de volver a sus orígenes literarios, y que entre ficción e historia no hay diferencias epistemológicas y metodológicas fundamentales, añadiendo, además, una peculiar "reconstrucción" de nuestro pasado historiográfico que asegura que siempre ha sido así, que la historia profesional nunca ha dejado de ser una variante más de la literatura; de la poesía, como diría Aristóteles. Una manera harto extremista, por consiguiente, de interpretar la revalorización actual del papel de la subjetividad del historiador en el proceso de conocimiento histórico que tiene conocidos precedentes filosóficos e historiográficos, marginados durante años por la hegemonía de las nuevas historias del neopositivismo, el marxismo y Annales. Revalorización ilimitada del historiador como autor y escritor que conecta, de manera difusa, con la tendencia a juntar la historia con las humanidades, pero separándola de las ciencias, cuando lo que distingue al historiador de otros escritores sobre el pasado es su carácter científico (según nuestra definición actualizada).

Estamos, pues, ante la estación final del "gran retomo" de la historia, más acá de sus primeros pasos como ciencia "positiva".

34. Hemos tenido que abrir por esta razón un nuevo apartado temático en el tomo III de las Actas, que no estaba previamente en el programa del Congreso.

35. La "marcha atrás" de la historia como disciplina académica encuentra su tope final al reintegrarla a la literatura, de cuyo seno nació antes de desarrollarse como ciencia y profesión, ya no puede retroceder más. 
Retroceso que equivale, cualquiera que sea la intención de sus promotores y protagonistas, a una tercera ${ }^{36}$ proclamación del "final de la historia" en poco tiempo, esta vez directamente como actividad profesional, docente e investigadora, porque de algo podemos estar seguros: nadie nos va a pagar por investigar o enseñar historia- ficción ${ }^{37}$. La propuesta que concibe la historia como un estilo literario más es la última consecuencia tanto de la postmodemidad radical como de la incontrolable bola de nieve que trae consigo el "giro positivista". Pero tiene algo bueno que ya mencionamos: la crisis epistemológica de la historia, que llevamos arrastrando desde hace años, toca de este modo fondo. Para evitar la desprofesionalización de la historia sólo queda ahora el camino que, desde Historia a Debate, hemos defendido en estos años 90: reconstruir el paradigma común de los historiadores sin romper con el siglo $\mathrm{XX}$, porque, visto lo visto, la crítica del positivismo a la historia literaria sin documentos, la crítica de Annales a la historia positivista tout court, la crítica del marxismo a una historia sin teoría ni compromiso, ¿no son hoy más necesarias pese a su insuficiencia- que nunca? ¿Es racional historiográficamente "rehabilitar" el positivismo o la historiaficción y correr un tupido velo sobre el neopositivismo, la historiografía marxista y la escuela de Annales ${ }^{38}$ ? La respuesta sólo puede ser afirmativa desde un posicionamiento historiográfico $-\mathrm{y}$ seguramente político- - reaccionario sin concesiones, que son los menos de los casos a los que nos referimos cuando hablamos de "marcha atrás" de la historiografía.

36. Las dos primeras proclamaciones del "fin de la historia" en la década de los 90 (también historiográficamente acelerada), se las debemos a Fukuyama y al posmodemismo radical: el fracaso de éstas abre las puertas al último "fin de la historia" animado por los literatos.

37. Claro que, a diferencia del "giro positivista", esta última vuelta de tuerca, el "giro narrativista”, en su versión más genuina (deconstmccionista y radical), es más teórico que práctico, de ahí la paradójica compatibilidad entre ambas fases de "retomo al pasado".

38. Hay una manera que suele pasar desapercibida de "traicionar" las nuevas historias: decir una cosa en público y hacer otra en privado. 
132 EL TALLER DE LA HISTORIA 2

El "retomo al pasado" con el que, ilusoriamente ${ }^{39}$, se pretende colmar el vacío que han dejado los grandes paradigmas del siglo XX tiene así y todo de "positivo" "la reacción que supone a la "ofensiva" del pensamiento posmodemo en su versión extrema hoy en clara decadencia-, pero no soluciona los problemas actuales de la historia, su redefinición como ciencia y su adaptación a la sociedad global del nuevo siglo, más bien los agrava con su incontrolable estrategia de "vuelta al pasado".

Preparado por los retornos temáticos, el regreso metodológico a Ranke, Langlois y Seignobos, es una fuite en arriére que, de seguir adelante, nos alejaría definitivamente de las actuales ciencias sociales y naturales, ubicadas en el pos-positivismo, y de la sociedad del nuevo siglo, que demanda crecientemente historia. El positivismo historiográfico de finales del siglo XIX, en Alemania, y principios del siglo XX, en Francia, no es una respuesta historiográfica con futuro por razones de contexto cronológico que nadie debería comprender mejor que nosotros. Los historiadores se parecen más a su tiempo que a sus padres, y, en el siglo XXI, está fuera de contexto la ingenuidad cientifista que se desprende de las célebres frases: la "historia es conocer el pasado tal como fue", o la "historia se hace con documentos". De igual modo, ¿tiene sentido vincular la utilidad social de la historia, como en el siglo XIX, a Estados nacionales impugnados, internamente por las identidades nacionales, regionales y étnicas, y externamente por la globalización ${ }^{41}$ ?

39. Olvidando que la pervivencia del (neo)positivismo historiográfico, en la segunda mitad del siglo XX, fue posible en alianza tácita con el marxismo y Anuales, "El paradigma común de los historiadores del siglo XX”, Medievalismo, Madrid, $\mathrm{N}^{\circ} 7$, 1997.

40. Jacques Revel nos propone sustituir historia "positivista" por historia "positiva", "Ressources narratives et connaissances historiques”, Enquéte, N 1, París, 1995, p. 55.

41. Por eso está destinado al fracaso historiográfico y político todo intento de resucitar hoy una historia de España que siga el modelo de la historiografía nacionalista que nació en el siglo XIX y dominó, dramáticamente, parte del siglo XX, y que ilustra también, paradójicamente, muchas historias de las nacionalidades y regiones que conforman España. 
Si de lo que se trata es de buscar en el pasado historiográfico - "receta" muy de historiadores - las certezas perdidas muchos de nosotros preferiríamos volver a Bloch, Febvre, Braudel, Le Goff, Carr, Hobsbwam, Thompson, Vicens Vives, Tuñón de Lara, etc., cuyas críticas al positivismo y a la historia tradicional de raíz decimonónica, y sus aportaciones renovadoras, recobrarán actualidad en la medida que el "giro conservador" quiera imponerse. Aunque somos conscientes de que los paradigmas que representan estos grandes historiadores del siglo XX son, asimismo, incapaces de ofrecer soluciones a los problemas epistemológicos e historiográficos actuales o a los avances de la investigación en temas tan dispares como la historia oral, la historia de las mujeres, la historia ecológica, la historia poscolonial o la historia mundial como historia global. De ahí que preconicemos avanzar en la construcción del(os) nuevo(s) paradigma(s) sin hacer tabla rasa del pasado, procurando síntesis creativas, también entre las nuevas y las viejas historias, o entre la historia como ciencia y su prehistoria literaria, pero con los ojos puestos siempre en el presente crítico y en el futuro por construir.

Aspiramos a que este II Congreso Internacional Historia a Debate contribuya a que la parte de la historiografía que camina hacia atrás, invierta su marcha. Los historiadores debemos encontrar nuestras "terceras vías" ${ }^{42}$, convencidos, como estamos, de que no nos sirven ya los paradigmas del siglo XX, pero menos aún los del siglo XIX. Es preciso pasar del "gran retomo" a la "gran síntesis" de la historia, de forma que la crisis, que nosotros entendemos como cambio de paradigmas, dé lugar a la (tercera) revolución historiográfica que asegure una nueva primavera para la historia.

El momento es oportuno. Cuando la historia de los acontecimientos se acelera, cuando la sociedad revolucionada presta atención de nuevo a la historia, sólo falta que los historiadores nos pongamos a la par. Y si lo hacemos la historia en el siglo que viene

42. Con la precaución, naturalmente, de no imponerla "bombardeando" a las demás alternativas en nombre de la globalización o del nuevo paradigma. 
134 EL TALLER DE LA HISTORIA 2

llegará a ser, como en algunos momentos y países del siglo XX, una referencia inexcusable para las ciencias sociales y las humanidades, y para las preocupaciones de los ciudadanos a la hora de la acción educativa, cultural y política.

\section{RECONSTRUCCIÓN Y REFORMA}

En el Libro de abstracts del Congreso se argumenta que, en el debate modemidad/posmodemidad, hay tres posiciones: los deconstructores-posmodemos, los neoconservadores y los reconstructores-reformistas ${ }^{43}$. El eje que, en nuestra opinión, permite superar mejor, dialécticamente, la confrontación modemidad/posmodemidad, cuya prolongación genera el síndrome paralizante del "vacío de paradigmas", es la reconstrucción y reforma paradigmática. Después de la crítica destmctiva del posmodemismo y de la reacción neoconservadora de los "retornos", sólo queda por probar - algunos lo estamos haciendo desde hace años- la reconstrucción orientada hacia un futuro que es, y será todavía más, global.

En el siglo XXI la escritura de la historia estará, en cada país, más condicionada por la historiografía internacional que nunca. El papel de la historiografía global irá creciendo en relación con las historiografías nacionales, gracias a las nuevas tecnologías de la comunicación y a los procesos de integración transnacional en el terreno económico, político, cultural y académico.

La historiografía, como la historia, no se repite más que como comedia o tragedia. Por lo tanto no volverán las grandes escuelas del siglo XX, y menos las del siglo XIX. La salida de nuestra disciplina es hacia adelante.

Necesitamos por consiguiente otro concepto de oficio de historiador, más allá del positivismo, que no reduzca nuestro trabajo

43. Resumen de J. M. Santana para la Mesa L ("Posmodernidad, historia y nueva ilustración"), citando a Augusto Klappenbach, Ética y posmodernidad, Alcalá de Henares, 1991. 
a las ciencias auxiliares de la historia, las cuales nos merecen un respeto absoluto - dependemos a menudo de ellas - pero la función del historiador ha de transcender las fuentes y la crítica de las fuentes o no habremos aprendido nada de la historia y de la historiografía.

Necesitamos, asimismo, adherimos a otra noción de historia como ciencia, menos anacrónica, más actual. Los historiadores tenemos que poner al día nuestro concepto de ciencia, que hoy, para las ciencias sociales y más aún para las ciencias naturales, es menos objetivista y más relativista ${ }^{44}$. Hace casi veinte años que se habla de una "ciencia con conciencia", de una ciencia con sujeto ${ }^{45}$ no solamente con objeto. Sigue siendo para nosotros un misterio insondable como, en una parte considerable de la comunidad de historiadores, se ha conservado en formol, hasta finales del siglo $\mathrm{XX}$, el concepto decimonónico de lo que es una ciencia: una herencia de Ranke que viene de más atrás, de las ciencias de la naturaleza del siglo XVII ${ }^{46}$. Todavía hoy creen bastantes colegas, y estudiantes de historia ${ }^{47}$, que hacer ciencia es conocer la realidad "tal como fue", esto es, de manera "exacta" 48 . Ninguna ciencia natural se plantea esto hoy, y menos que ninguna la física o la biología, sujetas tanto o más que la historia a los condicionamientos internos de la comunidad de especialistas y externos de la sociedad y la política. Desde principios del siglo XX, desde la teoría de la relatividad, la teoría cuántica y el principio de incertidumbre de Heisenberg, se sabe que el sujeto del proceso de conocimiento interfiere sobre el objeto, y que las verdades que podemos conocer científicamente son aproximativas, condicionadas por el observa

44. Tesis 3 y 4 de La historia que viene.

45. Édgar Morin, Science avec conscience, París, 1982 (Barcelona, 1984).

46. Véase la nota 13.

47. Sin embargo otros nos manifiestan en clase no entender la insistencia de sus profesores en defender la historia como ciencia.

48. Cierta crítica posmodema también se ha basado, por oportunismo, en este concepto periclitado y cuasi religioso de ciencia para afirmar que "la historia no es una ciencia", ni que tal cosa pueda existir. 
136 EL TALLER DE LA HISTORIA 2

dor y sus circunstancias, siendo la más importante de ellas la opinión mayoritaria de la comunidad de especialistas. No es científico, en consecuencia, separar objeto y sujeto en el proceso de conocimiento, en este caso aislar el historiador del proceso de conocimiento histórico. Si lo hacemos caeremos con toda seguridad en la inexactitud histórica. En suma, el positivismo historiográfico ha dejado de ser científico según los criterios de la práctica y la teoría de la ciencia actuales.

Solamente una atenta mirada a las ciencias de la naturaleza, y a la filosofía y la historia de la ciencia, nos convencerá de que no podemos ser en esto más papistas que el papa, y si un científico "duro" no concibe verdades absolutistas y objetivistas, ¿por qué habremos de seguir "creyendo" en ello los historiadores? La historia sólo seguirá siendo considerada una ciencia si ponemos todos al día nuestro concepto de ciencia ${ }^{49}$. De ahí la futilidad del "giro positivista" y su papel involuntario en la "des-cientificación" de la historia profesional propugnada por el narrativismo radical. La vuelta a Ranke, cualquiera que sea la intención de sus partidarios conscientes, aparta la historia de la ciencia, tal como hoy se entien$\mathrm{de}^{50}$, y allana el camino para su "reintegración" en el seno de la literatura.

La reconstrucción y reforma del paradigma de la historia tendrá que hacerse con nuevos y viejos materiales, con todo el capital acumulado por nuestra disciplina desde mediados del siglo XIX, pasado por el filtro de la crítica y la autocrítica, y con las tendencias historiográficas, sociales y tecnológicas, posteriores a la nueva historia. Estamos todavía en el proceso (inevitable) de conformación de esta nueva matriz disciplinar.

49. Uno de los efectos principales de la actualización de la historia como ciencia será la ampliación de nuestro concepto de interdisciplinariedad, como veremos en el capítulo de propuestas.

50. El problema de fondo del fracaso (parcial) de la experiencia renovadora de la escuela de Armales, la historiografía marxista y el neopositivismo historiográfico estuvo en su incapacidad para mantener la historia científica a la altura de la ciencia relativista del siglo XX. 
Somos grandes defensores de aplicar las teorías de Thomas S. Kuhn sobre la historia de la ciencia a la propia historia, con los cambios que aconseja el debate que siguió a sus propuestas y nuestra propia experiencia historiográfica. En La estructura de las revoluciones científicas (1962) se dice que el conocimiento científico no es acumulativo, sino que avanza a saltos, a través de revoluciones científicas. En realidad el conocimiento científico es, simultáneamente, acumulativo y rupturista. La revolución historiográfica del siglo XX, protagonizada por Annales, el marxismo y la cliometría neopositivista, ¿no continúo de alguna forma, malgré tout, el positivismo de fines del siglo XIX? La revolución historiográfica que estamos incubando (que algunos quisieran celebrar como contrarrevolución), ha de continuar en cierto grado, se quiera o no, las nuevas historias del siglo XX para avanzar: las aportaciones de las vanguardias historiográficas del siglo XX forman parte ya del capital historiográfico acumulado, está por ver en qué medida y en qué forma entrarán en el nuevo paradigma.

¿Cómo combinar, por lo tanto, las viejas escuelas y debates del siglo XIX (que aparentemente vuelven) con las nuevas escuelas del siglo XX (que parecen retroceder) para contribuir a dar respuestas actualizadas a los problemas teóricos y prácticos de la historia del siglo XXI? Desde luego no de manera ecléctica, sumando componentes contradictorios, sino a través de un nuevo paradigma o consenso, común denominador de sumandos diversos, pero compatibles en una matriz disciplinar evidentemente plural. Los cambios históricos, ¿no fueron habitualmente la lucha de lo nuevo contra lo viejo ${ }^{51}$ ? En historiografía ha ocurrido algo parecido con los cambios de paradigmas hasta la crisis actual donde vemos la relación viejo/nuevo se ha vuelto, como tantas otras cosas, más compleja, lo vimos en lo relativo a las generaciones de historiadores.

Uno de los motores de la renovación historiográfica a lo largo del siglo XX ha sido pues la dicotomía viejo-nuevo. Ahora, sin 


\section{EL TALLER DE LA HISTORIA 2}

embargo, lo viejo se presenta como nuevo (y en alguna medida lo es), y cada vez escasean más las auténticas novedades historiográficas. ¿Qué nuevos planteamientos historiográficos han surgido en los años 90, si exceptuamos los relacionados con la globalización ${ }^{52}$ ? Todavía algunos colegas mantienen como "última" novedad historiográfica la microhistoria iniciada, en 1980, por un grupo de historiadores italianos que reniegan hoy de ella, quince años después ${ }^{53}$, de forma parcial pero lúcida ${ }^{54}$, diciendo que "es un instrumento útil pero no es la solución a los problemas de la historia en este momento", porque lo que necesitamos hoy es más bien "macrohistoria", "interpretación global" y "re-síntesis"

Y no surgen grandes novedades historiográficas porque todos los temas han sido "descubiertos", el avance historiográfico ya no se puede reducir a contraponer temáticamente lo viejo con lo nuevo. Una línea de investigación realmente nueva ha de responder, además, a los graves desafíos a los que se enfrenta la historia profesional en este momento, para lo cual es preciso una carga teórica y historiográfica que las simples propuestas, nuevas o viejas, de temas y enfoques de investigación son insuficientes $\mathrm{y}$, a medio plazo, frustrantes. Por eso defendemos que el historiador del futuro "reflexionará sobre metodología, historiografía y teoría de la historia, o no será" ${ }^{56}$. Lo cual no quiere decir que todos y cada uno de los historiadores futuros han de dedicarse a la reflexión historiográfica, sino que un alto nivel de "conocimiento no basado en fuentes" decidirá, mañana más que ayer, la calidad de una monografía con base empírica. ¿No estamos observando ya que se pro

52. La historia poscolonial a partir de los "estudios subalternos", la historia mundial como historia global, nuestro propio enfoque global hacia un "nuevo paradigma"; en todos estos casos, se propone la síntesis como vía de renovación.

53. “Entrevista a Giovanni Levi”, Prohistoria, Rosario, № 3, 1999, pp. 187-188, 191.

54. Al sentido autocrítico le pasa lo mismo que al debate: no es un uso académico normal, reglado.

55. Tal es nuestra posición desde el I Congreso, véase si no la tesis 7 de La historia que viene.

56. Tesis 13 de La historia que viene. 
duce mucho cuantitativa y académicamente pero escasean obras de investigación que dejen huella, que digan algo realmente distinto? ¿Y cómo decir algo distinto, nuevo, si no se reflexiona sobre lo que se hace?

Se progresa metodológicamente a través de la síntesis, pero, para que ésta no sea ecléctica e inútil, es menester agudizar la reflexión, que tampoco sirve de mucho al margen de la investigación empírica ${ }^{57}$. Estamos convencidos de que una buena vía para la creatividad historiográfica, en este momento, es la confluencia de diversas líneas de investigación, el mestizaje de géneros historiográficos. Síntesis y reflexión, reconstrucción y reforma, investigación y debate: ahí están algunas de las bases esenciales del cambio de paradigmas que necesitamos, que estamos construyendo, queramos o no, con nuestros esfuerzos individuales, acciones y omisiones, pasos atrás y pasos adelante. Luces y sombras que se pueden deducir también de los resúmenes y textos que habéis enviado previamente al Congreso.

\section{DIAGNÓSTICO POSIBLE}

Hemos tenido, como es lógico, dificultades para cerrar el programa porque al conceder, de entrada, a ponentes y comunicantes, libertad para elegir tema y mesas redondas, se produce un desequilibrio entre las diferentes partes del congreso. Habría sido más cómodo orientar de antemano los temas y las mesas redondas donde podría o debería intervenir cada uno, pero habríamos renunciado así a una primera y valiosa aproximación a la situación historiográfica global. Coyuntura nada sencilla de diagnosticar, mientras no se desarrollen las nuevas redes historiográficas globales, que comunican - como intentamos en $\mathrm{HaD}$ - en tiempo real y sin fronteras de nacionalidad o especialidad a los historiadores del

57. Una dificultad para una mayor colaboración entre historia y filosofía de la historia es que los historiadores no solemos tener en cuenta los trabajos de los filósofos de la historia, y éstos tampoco las investigaciones de los historiadores. 
140 EL TALLER DE LA HISTORIA 2

mundo. Las conclusiones que se puedan sacar de nuestra Encuesta Internacional "El estado de la historia", con más de quinientas respuestas obtenidas hasta el momento, de historiadores de todo el mundo, supondrán al respecto un paso adelante.

Son dos las cuestiones que, a priori, nos parecieron claves desde los prolegómenos del II Congreso ${ }^{58}$ : historia / literatura y el problema de la ciencia, por un lado; historia / sociedad y el compromiso del historiador, por el otro. Alrededor de estos dos ejes se resumen buena parte de los debates y reflexiones habidos, si bien han destacado, tanto en el congreso presencial como en el virtual, antes, durante y después del II Congreso, temas asimismo fundamentales como globalización e historia, pasado y futuro, enseñanza de la historia, problemas profesionales, poscolonialismo, mujeres/hombres o la emergencia de las historiografías latinas ${ }^{59}$. Tendremos tiempo de reflexionar y escribir sobre todo ello. Vamos a transcribir todas las mesas redondas, y leer con calma, ponencias y comunicaciones, debates orales y resúmenes...

En cualquier caso, llama la atención el desplazamiento geográfico de los centros generadores de iniciativa y polémica historiográficas $^{60}$, menos sujetos que nunca a la jerarquía centro/periferia. Los debates capitales historia-literatura e historia-ciencia han venido de los Estados Unidos, que se ha transformado en un importante foco de las discusiones que tienen que ver con la historia desde 1989 y el "final de la historia" de Fukuyama. Sin embargo, el gran debate sobre el compromiso renovado del historiador, viene de América Latina, que aporta o puede aportar a la historiografía internacional una frescura inigualable en las relaciones historia/ sociedad y pasado/presente, como se ve en el propio congreso.

58. Véase Carlos Barros, "El dilema de los historiadores", La aventura de la historia, Madrid, N 14, diciembre 1999, pp. 108-109.

59. Véase el debate poscongresual sobre "Lo latino en la historiografía global" en www.hdebate.com.

60. Nos preguntamos si es posible que prospere hoy una nueva iniciativa historiográfica sin debate explícito. 
CARLOS BARROS 141

Frente al dinamismo del continente americano, la aportación historiográfica europea está en un impasse inquietante a causa del agotamiento de los antiguos focos innovadores, francés y británico, crecientemente dependientes de las relaciones con Norteamérica $^{61}$, y de las dificultades de la historiografía alemana para traspasar sus fronteras nacionales ${ }^{62}$. La irradiación internacional ${ }^{63} \mathrm{de}$ la parte de la historiografía española que Historia a Debate representa ya no sigue el viejo modelo de país que incide sobre otros culturalmente dependientes. Lo que se está imponiendo ahora es la multipolaridad de las iniciativas y la globalización de la comunicación. Se influye, o se puede influir, historiográficamente más por la conexión global que por el rol político-económico-cultural dominante del país de origen, que, lógicamente, no desaparece de las relaciones académicas e historiográficas internacionales.

Femando Devoto me comentaba, yendo para una mesa redonda que hicimos durante el congreso para una revista gallega ${ }^{64}$, su extrañeza ante mi información de que posiblemente el segundo grupo nacional en participación estaba siendo Argentina, asegurando que "los argentinos no estamos entre las historiografías más importantes del mundo". Yo ya no sé, sinceramente, qué historiografías serán las "más importantes" después de este cambio del siglo, ni qué cosa significará eso de "historiografía importante" en

61. A cuyas universidades están estrechamente ligados, cuando no integrados, hoy en día, destacados miembros de lo que fueron las tendencias Past and Presenty Annales.

62. El trascendental "debate de los historiadores" sobre la asunción del pasado alemán y el revisionismo historiográfico no tuvo casi trascendencia externa, pese a su interés ejemplar.

63. Durante el primer aniversario de nuestra página web hemos contabilizados entre 25.000 y 30.000 visitas de historiadores, en su mayor parte de Estados Unidos, España, Argentina y México, por este orden; y en nuestra lista de correo electrónico participan 850 colegas de más de 45 países, siendo los historiadores españoles, principalmente jóvenes, la primera minoría.

64. Xosé Manuel Núñez (moderador), Harvey J. Kaye, Fernando Devoto, Jacques Revel, Ciro F. Cardoso, Carlos Barros, "A función do pasado a debate. A historia das historias”, Tempos Novos, Santiago de Compostela, N²8, septiembre 1999, pp. 34-40 (también en www.h-debate.com). 
142 EL TALLER DE LA HISTORIA 2

el siglo XXI. En la Encuesta Internacional sobre "El estado de la historia" hacemos esta pregunta y veremos el resultado, que podemos adivinar diverso. Una cosa es cierta: ninguna historiografía euro-norte-americana tiene la capacidad demostrada, como se ve en el congreso, por la historiografía argentina para expresar y reivindicar, sin los habituales tapujos del oficio, la relación entre memoria e historia, pasado y presente. Y estamos en condiciones de aseverar que la vitalidad y la calidad de una historiografía nacional se va a medir, se está midiendo ya, por la relación entre academia y sociedad, entre historiadores y ciudadanos, contra la opinión de los practicantes más extremistas del "giro positivista".

Dijimos antes, que la globalización lo resuelve todo, para mal y para bien, haciendo posible una democratización de las interrelaciones académicas y culturales que altera las rígidas relaciones de dependencia historiográfica que hemos conocido desde finales del siglo XIX. Un buen ejemplo es la propuesta de la historiografía poscolonial derivada de los "estudios subalternos" en la India ${ }^{65}$. Peter Burke escribió y dijo en el I Congreso que la renovación pasaba más por la periferia que por el centro: "the contemporany historical world is polycentric in the sense that innovations now arise in many different places, notably in the so-called 'peripheries', in Europe and outside" ${ }^{\text {}}$. La verdad es que esta formulación, siendo cierta, hoy se ha quedado corta. Ahora habría que decir que la renovación historiográfica, venga de dónde venga, sólo puede ser global, no puede triunfar encerrada en los viejos Estados-naciones. Las iniciativas historiográficas pueden ser promovidas desde cualquier país ${ }^{67}$ pero sólo avanzan cuando adquieren una dimen

65. Está por hacer un gran debate sobre la virtual contribución de la historiografía poscolonial a la "nueva historiografía" mundial/global.

66. Historia a Debate, I, Santiago, 1995, p. 52.

67. La ventaja de los países poderosos con área de influencia (no sólo occidentales, también orientales; no sólo en el Norte, también en el Sur) es su peso político y cultural, y la ventaja de los países antaño dependientes es precisamente lo contrario: la falta de una tradición que lastre la audacia, el espíritu renovador y la adecuación a lo nuevo. 
sión internacional, mundial $/ g l o b a l{ }^{68}$. Sea desde la "periferia" sea desde el "centro", según los criterios tradicionales de jerarquía geopolítica, las innovaciones precisan ser globales en su dimensión y contenido.

La globalización económica, informativa y cultural, los procesos de integración supranacionales, desbordan al Estado-nación como marco de iniciativas, y conciben un nuevo sujeto de comunidades transnacionales, que intercambian información y generan consensos a una velocidad muy superior al sistema académico convencional fundamentado en puntuales actividades presenciales y lentas ediciones sobre papel, que naturalmente seguirán cumpliendo su función. La "nueva historiografía" que surge de la globalización informativa y académica sobredetermina ya las realidades historiográficas nacionales. En el campo historiográfico, como en tantos otros, dentro y fuera de la academia, el aislamiento nacional va a significar en el futuro inmediato un coste más gravoso, en especial en países con gran fuerza de la tradición y peso político, porque los otros no tienen más que ganar con la globalización historiográfica.

Dejo para el final algunas propuestas para el debate y el consenso sobre la reconstrucción y reforma del paradigma de la historia. Partimos de las conclusiones del anterior Congreso (La historia que viene) y de lo que hemos podido ver y discutir hasta el día de hoy, además de las reflexiones y experiencias personales. Todo ello con cierta provisionalidad, para esta intervención oral no dispongo de un texto escrito, matizaré más a la hora de redactarlo después del congreso ${ }^{69}$. Me concedo, pues, una libertad que no habéis tenido vosotros, que tuvisteis que presentar los textos antes de terminar el Congreso. Yo también hubiera querido cumplir con

68. La presencia en la red diferencia hoy las posibilidades de Estados Unidos respecto de Alemania o Francia; y el auge del español como segunda lengua occidental, explica asimismo la emergencia de lo latino en el mundo globalizado.

69. La última revisión del texto ampliado, pero fiel al esquema y a las palabras iniciales, que tiene el lector en sus manos, fue en julio de 2000, en el momento de corregir las pruebas de imprenta de las Actas. 
144 EL TALLER DE LA HISTORIA 2

esta obligación, pero hemos sido incapaces, en el caso de Israel Sanmartín y mío, por lo que decía al principio de la conferencia sobre eso de dar la misa y tocar la campana, pido disculpas por ello. La ventaja es que así intervengo más en caliente, al hilo del desarrollo del congreso.

\section{UNA HISTORIA MÁS NARRATIVA}

Una de las cosas sobre las que la preparación de este II Congreso me ha hecho reflexionar, de manera autocrítica, es el debate entre historia y relato, entre historia y ficción, cuya actualidad renovada nos ha sorprendido un poco ${ }^{70}$. Merecería la pena, es mi primera propuesta, intentar una historia más narrativa sin dejar de ser científica — según el concepto relativista del siglo XX, insistimos una vez más - y sin confundirla, claro está, con la novela histórica. Una "nueva historia narrativa" que trace límites entre el relato del historiador y el relato del escritor de ficción, que no diferencia como nosotros la realidad de la ficción, ni tampoco le interesa.

¿Cuántas veces caen en nuestras manos documentos de archivo de donde se puede deducir una realidad que supera a la ficción? De ellos, más que de la imaginación personal, se nutren frecuentemente los novelistas, concibiendo relatos cuya capacidad de asombramos, entretenemos y enseñamos, viene mayormente de los datos históricos reales, documentales, testimoniales. Y a la inversa, ¿por qué el historiador no ha de utilizar también dichos documentos/testimonios con trama, narradores y estilo, propiamente literarios? Estoy convencido de que, hallando las fuentes adecuadas, podríamos aprender de la literatura al mismo tiempo que competimos con ella. Brindando una verdad histórica relativa y cambian

70. En el programa del congreso habíamos contemplado la historia narrativa de manera subalterna, en la mesa K como parte del debate de la posmodemidad y el "giro lingüístico", cuando, en realidad, es más bien una consecuencia final del retorno de la vieja historia, favorecida por una crítica posmodema incapaz de ofrecer alternativas que tengan en cuenta las tradiciones historiográficas. 
te, a menudo plural, cuyo manejo exige un oficio y una experiencia que no están al alcance de los escritores de ficción histórica, con su ilimitada libertad para inventar personajes, diálogos y situaciones, que deforman motu propio - no involuntariamente como los historiadores profesionales - los hechos históricos de referencia.

Valdría la pena, por consiguiente, verificar prácticamente la posibilidad de "relatos históricos verídicos" en la frontera entre la ciencia y la literatura (desde el lado de la ciencia, por supuesto), con trama pero sin faltar al rigor. De Kuhn hemos aprendido que entre la ciencia y el arte hay elementos comunes, pero sabemos asimismo que existen capitales diferencias. ¿Podríamos, en trabajos que fuesen a la vez de investigación y de divulgación, ir de brazo de la novela sin por ello renunciar a hacer una historia seria? Habría que experimentarlo antes de contestar. Se ha dicho con razón, a partir de los trabajos de H. White y P. Ricoeur ${ }^{71}$, que toda historia es narrativa, y es cierto, pero de manera inconsciente, artesanal. Mi propuesta es debemos hacerlo conscientemente con el mismo rigor con el que investigamos desde otros enfoques.

La "nueva historia narrativa" puede ser, en consecuencia, una síntesis de futuro entre la "nueva" y la "vieja historia", y, además, un buen camino para reconstruir nuestra relación con la sociedad. ¿No sería importante que algunas obras de investigación fuesen leídas con tanto o más entusiasmo por parte de un lector profano que por parte de un especialista?

Otros historiadores como Georges Lefebvre, de tradición annaliste, o Jerzy Topolski y Ciro F.Cardoso, de tradición marxista, han apuntado o apuntan en esta misma dirección, la novedad es que nosotros planteamos pasar del debate teórico a la práctica, lo cual aportará con toda seguridad nuevos elementos para la reflexión y ayudará a construir el nuevo paradigma de la historia con viejos, nuevos y novísimos materiales.

71. La convergencia historia y narración que proponemos sería, desde luego, más compatible con Ricoeur que con White. 
146 EL TALLER DE LA HISTORIA 2

\section{UNA HISTORIA MAS COMPROMETIDA}

La segunda propuesta, que recoge asimismo cosas que se han dicho en el Congreso, es afirmamos en una historia más comprometida, más en contacto con la sociedad, sin menoscabo del rigor y de la verdad de los historiadores, que es lo que nos confiere la autoridad moral que ha de sustentar nuestro compromiso ético y social.

Una historia más comprometida con las causas sociales y políticas, nacionales y religiosas, pero no a la manera de la "historia militante" de los años 60 y 70. Debemos ser autocríticos con las historiografías de esos años, cuyos fracasos han creado las condiciones para el retomo presente de la vieja historia. Si hoy algunos colegas, en pleno "giro positivista", nada quieren saber de lo que sucede fuera de los muros de la universidad, algo tendrá que ver con los pasados excesos de una "historia militante" que sacrificó no pocas veces la objetividad histórica al servicio de un partido, ideología o causa, causándoles problemas de credibilidad, cuando no de viabilidad, a medio y largo plazo. La autocrítica que proponemos es política y historiográfica.

Nuestro compromiso historiográfico cara al nuevo siglo debe partir de la aceptación no dogmática de la legitimidad de compromisos de diversos signos. Cuando hablamos de historia comprometida parece que nos referimos a nosotros, historiadores progre$\operatorname{sistas}^{72}$, y así fue en los tiempos de hegemonía de la nueva historia, pero los "retornos" han puesto encima de la mesa otras ideologías y compromisos (coexistiendo en ocasiones en una misma institución de pasado progresista ${ }^{73}$ ), que hay que aprender a respetar, sal

72. Una constante de los historiadores conservadores ha sido siempre negar su compromiso, encubriendo sus ideas y valores bajo el manto de una inexistente neutralidad de la ciencia histórica, sin percatarse del daño que eso puede hacer a sus propias posiciones.

73. Es el caso de la Ecole des Hautes des Sciences Sociales de París donde en el presente cohabita la actividad (institucional) de formación permanente de ejecutivos de las grandes empresas de Francia con el apadrinamiento de inmigrantes sans papiers por parte de los directeurs d'études P. Bourdieu o J. Derrida. 
vo que sigamos creyendo en "verdades absolutas" o en métodos no intelectuales de imposición de las propias ideas. La otra opción sería "aniquilar" al adversario y eso se ha hecho políticamente, no hace mucho en América Latina, y aún se hace simbólicamente aquí y allá cuando se descalifica una posición historiográfica mediante una etiqueta política, religiosa o étnica, sin entrar en el fondo argumental.

Soy consciente de que la tolerancia que practicamos, y que forma parte de la identidad de Historia a Debate, no se puede aplicar con la misma facilidad par tout por razones de historia inmediata. Es el caso de Argentina, donde resulta difícil predicar la tolerancia (lo digo por experiencia propia), cuando hasta los años 80 la adscripción política de un profesor universitario fue motivo de expulsión del puesto de trabajo, o de algo peor. Estoy hablando pues de democracias consolidadas, de aquellos países donde hoy podemos discrepar académicamente (y políticamente) en unas cosas y coincidir en otras, sin problemas mayores ${ }^{74}$.

La relación diversa, incluso contradictoria, de los historiadores con la sociedad, la política y la ideología, nos fortalece a todos, a la historia y a la academia, siempre que se cumplan unas reglas mínimas de ética y profesionalidad, discutibles como todo en la vida, pero fundamentales.

Opino, como ya dije en la mesa redonda $\mathrm{G}$ sobre el compromiso, que debemos poner el rigor y la verdad de los historiadores por encima de cualquier compromiso político, ideológico, social o nacionalista. Y no estoy pensando en la salvaguarda, a veces imposible, del oficio de historiador de las luchas políticas y sociales, sino en la mejor contribución política e ideológica que podemos prestar a las causas que nos son próximas: la verdad histórica que conocemos.

74. Todo lo más comentarios off the record sin mayores consecuencias, aunque nos pueden producir vergüenza ajena, como los habidos sobre el protagonismo, en algunos debates del congreso, de "latinoamericanos" y "marxistas". 
148 EL TALLER DE LA HISTORIA 2

Verdad histórica que también suele ser diversa, incluso contrapuesta, por razones históricas (diferentes puntos de vista coetáneos de un conflicto social, político o militar), historiográfícas (diferentes enfoques o interpretaciones de los historiadores) y/o políticas (diferentes intereses y posiciones políticas de los investigadores), pero que remite siempre o debe remitir a una profesionalidad y a un "conocimiento basado en fuentes" cuya objetividad empírica, como bien sabe el lector, no idealizamos pero tampoco negamos, a sabiendas de que la última palabra sobre lo que es verdad histórica, en cada momento y en cada tema, la tiene la comunidad de especialistas.

Nuestra visión acumulativa y rupturista de la evolución de la ciencia histórica justifica un enfoque plural y sintético (que no ecléctico) de la renovación historiográfica y de la verdad histórica, que, en último extremo, consensúan las comunidades de historiadores en términos historiográficos, porque las fuentes se prestan a enfoques y conclusiones diferentes, y, en casos excepcionales, en términos políticos, en función de las relaciones de fuerza entre las distintas interpretaciones políticas de los historiadores y de los propios políticos. Como es el caso del debate 1997-2000 sobre la historia de España ${ }^{75}$.

En algún caso se puede plantear un dilema entre nuestra función como historiadores y nuestra adhesión política, sobre todo si esta es activa, militante: ¿a qué ser fiel, a la profesión y el rigor, o a las necesidades electorales, o de otro tipo, que pueda tener la organización de pertenencia, cara al mantenimiento de determinados mitos políticos ${ }^{76}$ ? No suele ser fácil decidir si se actúa, en dichas circunstancias, como intelectuales críticos o como "animales políticos", dependerá del interés circunstancial, de la implicación

75. Véanse en www.h-debate.com los mensajes distribuidos en la lista HaD.

76. Me refiero sobre todo a la manipulación mítica de la historia que hicieron el nazismo y el estalinismo en general, y el comunismo o el nacionalismo en particular; cuestión aparte son los relatos legendarios de transmisión oral de las culturas tradicionales, mitos "pre-históricos" en el sentido de estar constituidos antes de que la historia se estableciese como actividad crítica y científica. 
personal académica y/o política, del concepto de historia y de política que se tenga... ${ }^{77}$

Una cosa está clara a fines del siglo XX: los proyectos políticos, o de otro género, que practican una doble moral se hacen extraordinariamente vulnerables, cuando no acaban siendo barridos de la historia ${ }^{78}$. La mentira histórica como arma política es una forma de corrupción ideológica cada vez menos rentable, política y electoralmente, a causa de la democratización galopante del acceso a la información, y de la emergencia de una ética universal aplicada. Se puede anticipar $-\mathrm{y}$ desear- que, en el siglo XXI, historia y política serán más compatibles que en el siglo XX, excepto que la historia acabe perdiendo catastróficamente el reconocimiento social, deontológico y científico, en favor de dos fenómenos complementarios: la novela, por un lado; la erudición y el aislamiento académico de los historiadores, por el otro.

Auguramos, y predicamos, en consecuencia, mejores condiciones para la independencia de los historiadores y su valoración social como conocedores del pasado, desde una moral profesional para nada ajena al presente y al futuro.

Nos favorece, en este sentido histórico-ético, la globalización pacifista y justiciera que están poniendo en evidencia nuevos hechos como la actuación global de las ONGs, la persecución judicial — desde España - de la represión ejecutada por las dictaduras chilena y argentina, la demanda de un Tribunal Penal Internacional independiente, o la mediación pacificadora de la ONU en determinados conflictos, a pesar del traspiés de Yugoslavia, donde se

77. Un caso cercano: la mitificación por parte de cierta historiografía galleguista del mariscal Pardo de Cela como adalid del independentismo gallego frente a los Reyes Católicos contra toda evidencia factual de tipo histórico, véase Carlos BARROS, "Mitos de la historiografía galleguista", Manuscrits. Revista d'Historia Moderna, $\mathrm{N}^{\circ}$ 12, 1994, pp. 245-26; "Ascenso e caída do mariscal Pardo de Cela”, Antón Losada Diéguez. 10 anos dun premio, Poio, Concello de Carballiño, 1995, pp. 85-89.

78. Véase si no la política de la Iglesia católica, en la última fase del papado de Juan Pablo II, buscando la reconciliación con la verdad histórica en temas tan controvertidos como Galileo, la Inquisición o el nazismo. 
150 EL TALLER DE LA HISTORIA 2

aplicó precisamente un doble rasero por parte de los que apoyaron los bombardeos de la OTAN, y también por parte de aquellos detractores de la guerra y sus "efectos colaterales" que callaron ante las acciones serbias de "limpieza étnica". La inconsecuencia ético-universal resulta en estos tiempos costosa, en términos intelectuales y políticos: se está recuperando en la práctica la idea ilustrada del progreso moral y político de la humanidad ${ }^{79}$. El compromiso ético de respetar la verdad pasada que conocemos, está íntimamente ligado a la lucha actual por el respeto de los derechos humanos y cívicos de los pueblos y de los individuos. Si se avanza en la ética del presente se está favoreciendo la reconstrucción ética del pasado. Un buen ejemplo latino es como, casi treinta años después, crece la presión $-\mathrm{y}$ los resultados-, tanto interna como externamente (justicia global), para esclarecer la verdad y hacer justicia sobre lo sucedido durante las dictaduras militares en Chile y Argentina, de manera que estas transiciones a la democracia, inspiradas en un primer momento en la transición española y su estrategia de borrón y cuenta nueva, están desbordando el modelo inicial como consecuencia del cambio de mentalidades y contexto finisecular: la estabilidad política y democrática, a diferencia de los años 70, admite difícilmente la amnesia histórica sobre las atrocidades cometidas ${ }^{80}$. Frente a la tendencia dominante de una justicia global, ¿en qué lugar queda el revisionismo historiográfico de Nolte y compañía negador del holocausto judío? En un fenómeno anecdótico siempre y cuando los historiadores nos movilicemos, como se hizo en Alemania, contra la burda manipulación política de la verdad histórica que, en este caso, sirve al rearme ideológico de la extrema derecha. Para lo cual tiene que haber, como es obvio, una verdad histórica, ciertamente relativa pero

79. La pregunta es si la filosofía académica va por delante o por detrás de la sociedad y la política en cuanto esta recuperación de la idea de progreso; me temo que sea más lo segundo que lo primero, como dijimos la tarde del sábado en la mesa L.

80. Un antecedente fue la Comisión de la Verdad sudafricana, que no excluyó al propio Congreso Nacional Africano (en el gobierno) de sus investigaciones, y un reto para el inmediato futuro es, por ejemplo, destapar el problema de los centenares de desaparecidos en México en los años 70 y 80. 
que no se confunda con la mentira: el genocidio perpetrado por los nazis ha existido.

La incompetencia del posmodemismo más radical, para entrever las últimas consecuencias de su militancia anti-realista, explica su irreversible decadencia en el cambio de siglo. Es cierto que la razón ha engendrado monstmos, mas ¿será necesario advertir los horrores mayores que ha generado, genera y puede generar, la sinrazón y la irracionalidad? La humanidad no puede permitirse el lujo de hacer tabla rasa de la modernidad y la Ilustración, incluidas las luces y las sombras de su aplicación en el siglo XX. Cuando se cae en la tentación del borrón y la cuenta nueva, es imprescindible una historia que, desde una racionalidad crítica y autocrítica $^{81}$, analice el pasado para, desde la crítica del presente, construir un futuro mejor.

\section{UNA HISTORIA MÁS PENSADA}

Nuestra tercera propuesta es llevar a la práctica una historia más pensada. Escribimos, a raíz del I Congreso, que el buen historiador del futuro "reflexionará sobre metodología, historiografía y teoría de la historia, o no será" (tesis 13 de La historia que viene). Teníamos lógicas dudas sobre la pertinencia de una generalización de este tipo, pese a su justeza, para el conjunto de los colegas, a sabiendas de que la tradición y la formación del historiador para nada incentivan la reflexión sobre la historia y los historiadores, por lo que tiene de abstracción y, en consecuencia, de alejamiento de lo concreto: el sublimado documento histórico. Las funciones intelectuales del pensamiento social o de la epistemología son todavía consideradas por muchos historiadores - jóvenes y viejos-

81. Lo fácil es criticar la amnesia histórica de los "otros", lo difícil es hacer lo mismo con los "nuestros"; un ejemplo es la negativa de los historiadores más conocidos de la guerra civil española para entrar en el debate (ciertamente incómodo y planteado con acritud) sobre los acontecimientos de 1937 en Barcelona y la "persecución" del POUM, que tenemos abierto en $\mathrm{HaD}$ digital. 
como propias de filósofos, sociólogos y demás "teóricos", a quienes se cede con gusto la reflexión sobre la historia y la historiografía, el "pensar históricamente" que decía Pierre Vilar, que malamente podemos enseñar a los alumnos sin haberlo aprendido y practicado nosotros.

La experiencia de estos seis últimos años, y el diagnóstico sobre el oficio de historiador que podemos inferir a vuela pluma desde este II Congreso, nos lleva a ratificar, con fuerza si cabe redoblada, el camino emprendido por Historia a Debate de prestar especial atención a la metodología, la historiografía y la teoría de la historia, por tres motivos que son asimismo metas.

1) Para consolidar y dar continuidad a los avances indudables habidos en los años 90. Por vez primera en la historia de nuestra disciplina, la tarea de la auto-reflexión y de la investigación historiográfica se ha extendido a historiadores de varias generaciones, ganando en continuidad ${ }^{82}$. Estamos superando, por consiguiente, el carácter coyuntural, artesanal y elitista de aquellos escasos y providenciales escritos sobre metodología e historiografía de los "grandes historiadores" del siglo XX. La práctica y la teoría de la historia tienen que ir juntas, en nuestra opinión, desde el comienzo de la vida profesional, con el fin de racionalizar la escritura de la historia, practicar la "vigilancia epistemológica", equiparar la historia a otras disciplinas, y mantener una relación actualizada con la ciencia, con los alumnos y con la sociedad. En resumen, para que la historia que se escribe no se convierta en un palo seco, hay que pensar.

2) Para combatir con eficacia el "giro positivista" de aquel sector de la profesión que ha involucionado en el último lustro en sus posiciones historiográficas, abandonando los postulados de la nueva historia por los enfoques, temas y concepciones del viejo oficio de historiador: el retomo de la historia en su versión clásica y acrítica.

82. Una buena parte de los comunicantes al I Congreso era la primera vez que escribían sobre historiografía: la situación ha cambiado para bien en este II Congreso. 
No se trata de una actitud fácilmente defendible, y menos en público, ni demasiado consciente, por lo tanto la propia polémica diluirá parte del problema, pero no todo. Va a continuar la lucha entre una salida "hacia atrás" o "hacia adelante" de la crisis historiográfica finisecular. Combate demasiado soterrado para nuestro gusto. Condición previa para una resolución crítica finalmente progresista, con reales perspectiva de futuro, es hacer público el debate, la investigación y la reflexión sobre "adonde va la historia" ${ }^{\prime \prime 3}$, reivindicando en los hechos el "derecho de autodeterminación" de los historiadores frente a las pulsiones del mercado y del poder político; enlazando la reflexión sobre la historia - amplia pero minoritaria - con la práctica del conjunto de los historiadores, rehabilitando la primera persona del plural que nos define como comunidad de historiadores, más allá del individuo y sus circunstancias académico-gremiales.

3) Para conducir, en la medida de lo posible, el cambio de paradigmas historiográficos en marcha. La situación transitoria de nuestra disciplina está sujeta como vemos a flujos y reflujos, cuestionamientos y defensas, que se alternan rápidamente y que exigen perentoriamente un visión de conjunto, esto es, pararse a pensar de una manera colectiva qué está sucediendo, de dónde venimos y a dónde queremos ir. Porque no vale, lo estamos comprobando, en un período de "ciencia extraordinaria" como diría Kuhn, el método clásico de resolución de problemas, individualista y pragmático, más propio de los períodos pasados de "ciencia normal".

Nos estamos refiriendo continuamente a una historiografía del presente que se diferencia netamente de la convencional "historia de la historiografía" centrada en el estudio de los historiadores no contemporáneos, sus obras y las instituciones que los han alberga$\mathrm{do}^{84}$. Del mismo modo que hablamos de "historia inmediata" cuando

83. "La historia que queremos", Revista de Historia "Jerónimo Zurita", N ${ }^{5}$ 71,1995, pp. 309-345.

84. Esta historia tradicional de la historiografía aunque útil cae con frecuencia en el puro empirismo, aportando datos sin ideas que expliquen los cambios y las aportaciones; 
154 EL TALLER DE LA HISTORIA 2

analizamos los acontecimientos que acaban de suceder, o que están sucediendo, y que el historiador ha de enjuiciar con perspectiva histórica ${ }^{85}$, denominamos "historiografía inmediata" a la escritura de la historia y sus evoluciones actuales, en el pasado y el futuro inmediatos. La historia e historiografía inmediatas se distinguen, de la historia en general y de la "historia de la historiografía", respectivamente: a) por una implicación más transparente del historiador en los hechos históricos o historiográficos que se analizan así sobre el terreno ${ }^{86}$; b) por la provisionalidad de sus conclusiones, que han de permanecer abiertas, al igual que lo está la acción histórica o historiográfica que se estudia; y c) por la necesidad de considerar los factores externos al objeto de estudio -histórico o historiográfico- de tipo político, económico-social, ideológico y mental. La "historia de la historiografía" tradicional de matriz positivista ${ }^{87}$, que nosotros prolongamos cronológicamente hasta el presente, actualizando su definición, raramente tiene en cuenta la influencia de la política y la sociedad en los historiadores, sus obras y sus corrientes.

La historiografía inmediata que preconizamos $-\mathrm{y}$ que practicamos desde hace años - observa e interpreta de dónde viene y adonde va la historia que se escribe, se compromete con críticas y propuestas de futuro, y aún debería reflexionar sobre el sentido de la historia en colaboración/competencia con los filósofos inmersos en el tiempo presente, del mismo modo que tenemos que competir/ colaborar con los periodistas en el análisis de la historia inmediata

clasifiquen por períodos, paradigmas y tendencias; conecten la evolución de la historiografía con la historia social, política y mental, de su tiempo, etc.

85. Con posterioridad al II Congreso hemos abierto en HaD digital un apartado de "historia inmediata" con análisis, debates y testimonios de urgencia de historiadores sobre hechos de relevancia histórica que han tenido lugar en sus respectivos países.

86. Para la resolución de los dilemas que se pueden plantear son pertinentes las valoraciones historiográficas y políticas sobre la verdad histórica y el compromiso del historiador que hicimos más arriba.

87. Tampoco Thomas S. Kuhn tiene en cuenta los condicionamientos exteriores en sus planteamientos pos-positivistas sobre la historia y filosofía de la ciencia. 
y con los escritores en el enfoque y la difusión de los relatos históricos. ¿Por qué el historiador no ha de meditar, yendo de lo concreto a lo abstracto y viceversa, las implicaciones teóricas de la historia y de la historiografía? ¿Por qué la teoría vinculada a la historia inmediata hay que dejársela a los filósofos políticos? ¿No sería mejor una convergencia de historiadores, filósofos, politicólogos, sociólogos y periodistas en la interpretación, cada uno desde su ángulo de análisis, de los grandes hechos de la historia inmediata (y, si se quiere, no inmediata)?

Somos realistas, nuestros esfuerzos por dar prioridad a la metodología, la historiografía y la teoría de la historia chocan con la falta de formación — cuando no de interés, lo que es peor- de una gran parte de los historiadores profesionales ${ }^{88}$, lo cual, sumado a la pervivencia irredenta del positivismo, conduce, en ocasiones, a una minusvaloración curricular de este tipo de trabajos de investigación y reflexión, pese a la progresiva admiración intelectual que provocan entre quienes trabajan exclusivamente con datos empíricos. Este desfase entre formación y necesidades nos plantea la cuestión de la formación continua del profesorado universitario, en este caso de historia. La evolución del conocimiento, acelerada en los últimos tiempos, y las nuevas tecnologías, obliga a un reciclaje del profesorado en la enseñanza superior que, mientras no se impulse de manera institucional ${ }^{89}$, hay que suplir con esfuerzos individuales y colectivos que se apoyen en los sectores más dinámicos, menos gremiales o conformistas, de las comunidades de historiadores. Los avances conseguidos en poco tiempo, de lo cual la continuidad y los resultados de Historia a Debate son

88. Tiende a ampliarse al número de los que hemos optado por la auto-formación, como en cualquier otro campo de estudio especializado, donde uno tiene que buscar bibliografía y leer para estar al tanto.

89. El único momento en que un profesor / investigador de historia está "obligado", en España, a leer y escribir sobre metodología, historiografía y teoría de la historia es cuando prepara su proyecto docente para concursar a una plaza de profesor titular o catedrático; lo sabemos bien por la demanda habida de las Actas del I Congreso Historia a Debate, tenidos por muchos miembros de los tribunales como garantía de actualización de enfoques y debates historiográficos. 
156 EL TALLER DE LA HISTORIA 2

síntoma, causa y efecto, muestran por dónde van los vientos de la historia escrita. La débil institucionalización académica de este tipo de estudios y debates tiene de positivo, por otro lado, que facilita la libertad de crítica y unas relaciones horizontales y no corporativas imprescindibles para una salida renovadora del cambio historiográfico en marcha.

\section{UNA HISTORIA MÁS INTERDISCIPLINAR}

Nuestra cuarta propuesta es llevar a cabo una historia más interdisciplinar que supere las limitaciones y problemas de la formulación historia / ciencias sociales, característica de la historiografía renovada del siglo $\mathrm{XX}$.

El diálogo entre la historia y las ciencias sociales, impulsado desde los años 20 por Annales y otros grupos de historiadores, ha sido un magnífico motor de innovación historiográfica, pero acusa desde hace tiempo evidentes signos de agotamiento ${ }^{90}$. La relación de la historia con las ciencias sociales atraviesa una profunda cri$\operatorname{sis}^{9}$ ', cuya resolución debería apoyarse, en nuestra opinión, en tres pilares: A) volver a definir la historia como ciencia social y, simultáneamente, como parte de las humanidades, desbordando dialécticamente la bipartición ciencias/letras; B) superar la dependencia en la que ha caído la historia, respecto de otras disciplinas, en determinados ámbitos de la investigación y la reflexión; C) ampliar cualitativa y cuantitativamente, hacia dentro y hacia fuera, el campo de la interdisciplinariedad de la historia, en el camino de una multidisciplinariedad más plena.

La primera insuficiencia del principio de interdisciplinariedad de la nueva historia difundida en los años 60 y 70 es su restricción

90. La falta de resultados del toumant critique propuesto por la revista Annales, a finales de 1989, tiene que ver con la inadecuación y estrechez, sesenta años después de su formulación, de la relación historia-ciencias sociales para solucionar los graves problemas epistemológicos, historiográficos, metodológicos y sociales de la historia a finales del siglo XX. 
a determinadas ciencias sociales, en ese momento emergentes. La historia sólo se podrá afirmar como ciencia social de nuevo tipo, y cooperar en igualdad con otras ciencias sociales y disciplinas humanísticas, si se aplica a sí misma el criterio metodológico y epistemológico de la interdisciplinariedad y extiende, al mismo tiempo, el diálogo a todas los saberes, desde las humanidades (filosofía y literatura, sobre todo) hasta las ciencias de la naturale$\mathrm{za}^{92}$, pasando por las nuevas disciplinas surgidas de la sociedad de la información y las nuevas tecnologías. En resumen, se trata de reafirmar la unidad interna de la historia como disciplina para poder multiplicar sus opciones de colaboración a todas las ciencias y las letras, cuestionando la obsoleta (desde un punto de vista pospositivista) división del saber humano en "dos culturas" enfrenta$\operatorname{das}^{93}$.

La interdisciplina ha de empezar, pues, por nosotros mismos. No es coherente buscar la colaboración con disciplinas alejadas de la historia mientras se conservan inhiestas las murallas entre las diferentes áreas de conocimiento histórico, sustentadas por las corporaciones correspondientes. Es menester hacer converger especialidades históricas distintas, explorando interfaces entre historia medieval e historia moderna, historia económica e historia de las mentalidades, historia general e historia del derecho, historia del arte e historia de la literatura, etc. Tenemos al respecto la experiencia reciente de la convergencia de la historia social con otros géneros historiográficos: historia de las mentalidades, historia política, historia cultural $^{94}$. El mestizaje de diferentes líneas de investiga

91. Es lógico que la crisis de la historia condicione su relación con otras disciplinas, y también lo inverso.

92. Marc Bloch se equivocaba, visto el problema desde el presente, cuando decía que la historia no es la ciencia del pasado, en general, sino solamente la ciencia del pasado humano: ahora sabemos que la historia de los hombres es inseparable de la historia del medio natural.

93. Atención al matiz: negamos que ciencias y humanidades sean formas antitéticas del conocimiento no que existan fronteras entre la ciencia y el arte o la ficción.

94. "La historia que queremos", Revista de Historia "Jerónimo Zurita", № 71,1995, pp. 309-345. 
158 EL TALLER DE LA HISTORIA 2

ción histórica es fuente segura de creatividad historiográfica, por lo que tiene de síntesis dinámica, según ya comentamos. Parafraseando un lema publicitario televisivo de hace unos años podríamos exclamar que "hay otros mundos, pero están en éste", el continente de la historia.

Porque está por desarrollar plenamente la colaboración interdisciplinar entre historiadores de diferentes áreas y especialidades. Aplicar el principio interdisciplinar a la propia historia ${ }^{95}$ posibilitará una cooperación más equilibrada y complementaria con otras disciplinas. Si no es así, la interdisciplina extema de la historia seguirá traduciéndose en una fragmentación interna que nos hace más dependientes de otras disciplinas como la sociología, la antropología o la literatura ${ }^{96}$. La clave de una contribución interdisciplinar original de la historia está en no olvidarse de ella misma. Verbigracia, la nueva historia narrativa que proponemos solamente podrá ofrecer algo distinto, incluso superior, a la novela histórica, si se aprovechan los avances de los nuevos géneros historiográficos (historia social, historia de las mentalidades, historia política del poder, historia de las mujeres...) para dotar a "relatos verídicos" de los historiadores de la profundidad y el atractivo del rigor histórico, concepto éste propio de la historia no de la literatura.

¿De qué otro modo podemos reunificar el archipiélago de los fragmentos en que se ha convertido la disciplina de la historia? La implosión de los grandes paradigmas del siglo XX, el hiperdesarrollo de las monografías especializadas y el posmodemismo ambiental, han engendrado, desde los años 80 , un vasto archipiélago de islas e islotes que de alguna forma hay que conectar reticularmente. La especialización supone riqueza pero también heterogeneidad y disgregación'. Lo que planteamos es unir los diversos géneros y subgéneros historiográficos mediante "puentes" de di

95. Lo que hemos bautizado como "interhistoria" en la tesis 11 de La historia que viene.

96. Dependencia metodológica y epistemológica que se traduce en involución positivista y oposición a toda interdisciplinariedad por parte de algunos historiadores. 
ferentes tipos, como en esos Estados o regiones-archipiélagos que resuelven el problema de la insularidad construyendo todo tipo de conexiones - por tierra, mar y aire - para mantener relacionadas las múltiples islas pequeñas, medianas y grandes. La red multiforme que preconizamos, hoy más fácil gracias a Internet, ha de servimos en consecuencia para reconstruir las comunidades de historiadores, nacionales e internacionales, por encima o a través de las compartimentaciones académicas.

El fragmento más pequeño del archipiélago de la historia es el ego imaginario de cada historiador. El individualismo historiográfico aparentó inundar la profesión durante los últimos quince años, pero la realidad colectiva siempre se impone ${ }^{97}$. Historia a Debate quiere contribuir, con su práctica de recuperación del "espíritu de escuela" historiográfica, a tejer la gran red que reunifique el archipiélago de la historia, sin menoscabo de la identidad y del desarrollo libre de cada género historiográfico ${ }^{98}$, presente o futuro, ni de la necesaria colaboración con aquellas ramas del saber científico y cultural que sean útiles para cada enfoque de la investigación.

En resumen, ¿cómo hacer de la historia el centro del estudio de la historia a la vez que se intensifica su interdisciplinariedad? Es tarea más fácil de decir que de ejecutar, como todo aquello que suponga hacer varias cosas al mismo tiempo, a lo cual debemos acostumbramos porque estimamos se va a convertir en regla en el mundo global y complejo, plural y multicultural, que viene.

97. La caída de los grandes paradigmas ha creado la ilusión de una originalidad historiográfica y personal inexistente; las posturas de los historiadores ante la crisis se pueden resumir en cinco tipos principales: 1) tradicionales (viejos y nuevos), 2) continuadores de las nuevas historias de los 60 y 70, 3) posmodemos o escépticos, y 4) reconstructores-reformistas.

98. Tal es el sentido de nuestra propuesta de reintegrar el paradigma de la historia de las mujeres a la historia general para su consideración en las investigaciones donde sea pertinente, al tiempo que se refuerza la especialidad historiográfica, "La historia de las mujeres en el nuevo paradigma de la historia”, La historia de las mujeres en el nuevo paradigma de la historia, Madrid, 1997, pp. 55-61; véase asimismo el debate en la mesa O, publicado en el volumen III de estas Actas. 
160 EL TALLER DE LA HISTORIA 2

\section{UNA HISTORIA MAS GLOBAL}

Nuestra penúltima propuesta para la historia que viene, mejor dicho que está ya aquí: la historia ha de ser más global.

El primer argumento es la globalización que está unificando la historia del mundo. De modo que cuando hablamos de "historia global", hay que precisar si nos estamos refiriendo a la "historia mundial" o a lo que la nueva historia llamó "historia total". Esa nueva acepción del término "historia global" como "historia mundial" abre la posibilidad de una nueva (con precedentes ilustres) línea de investigación", que, como ha sucedido otras veces, puede arrojar luz sobre un pasado que ha sido estudiado preferentemente en los marcos espaciales y políticos del Estado-nación. Si la historia universal, concepto eminentemente filosófico, deviene con la globalización en historia inmediata, habrá un motivo más para hablar de nuevo paradigma de la historia.

Ahora bien, esta nueva acepción de la historia global no debe hacemos olvidar su noción primigenia. La ambición, hoy demasiado perdida, de hacer una historia total ${ }^{100}$ ha de encontrar en el futuro nuevas formas, aprendiendo de los errores pasados ${ }^{101}$. Con tal objeto hemos introducido en el programa del congreso un epígrafe temático sobre “¿Cómo hacer historia global?”. La escasa respuesta recibida — no esperábamos más - nos plantea un interrogante inquietante: ¿vamos a continuar con la parcelación de la historia en tiempos de globalización? No creo que pueda sobrevivir, jugando un papel (al menos como en el siglo XX), una historia fragmentada en un mundo global, tanto si nos referimos a la fragmentación espacial y nacional del objeto, como a la fragmentación

99. Hemos iniciado, después del II Congreso, un debate sobre "World History/Global History" que se puede consultar también en la web de HaD.

100. Preferimos usar el término de "historia global": lo "global" sugiere límites finitos, materiales y abarcables en contraposición a la infinitud, tendencialmente idealista e utópica, de lo "total".

101. Véase la tesis 10 de la Historia que viene. 
del tema y del método que provoca la proliferación de especialidades.

Lo global del objeto de investigación no solamente tiene que ver con la escala "micro" o "macro" de los fenómenos, sino también con los enfoques sintéticos, amplios, de conjunto, de cada tema de estudio. En este último sentido, la historia global tampoco es cosa del pasado historiográfico sino del futuro, siempre y cuando la contemplemos como punto de partida de las investigaciones no como el "objetivo inalcanzable" de los nuevos historiadores de los 60 y 70, como una práctica no como una teoría indemostrada y sin concreta aplicación.

La actual demanda social y política de historia para la divulgación y la enseñanza, nos exige una historia de conjunto, no cuarteada, y si los herederos de la historiografía antaño renovadora, proveniente de Annales y del materialismo histórico, no somos capaces de proporcionar alternativas, retomará, al igual que pasa con otros temas, la vieja historia: serán las síntesis narrativas quienes ofrezcan —está sucediendo ya - las respuestas adecuadas, siguiendo los viejos criterios de la cronología y la historia de los "grandes" hombres, instituciones y acontecimientos.

Una cuestión a decidir es si los nuevos enfoques globales formarán parte del proceso de investigación o se reducirán, como hasta ahora, a modos de exponer sintéticamente, con fines didácticos, los productos de unas investigaciones especializadas, fragmentadas, con un resultado a menudo indigerible para el lector. La racionalidad historiográfica debería animamos a ensayar aproximaciones globales - también mediante la nueva narrativa históricaque unifiquen la investigación y la divulgación, ¿seguirá este camino la historiografía del nuevo siglo? Sería desde luego la mejor opción, y las nuevas tecnologías favorecen enormemente dicha convergencia, pero, como bien sabemos, la racionalidad epistemológica y metodológica no lo es todo, y a veces ni siquiera es lo más importante a la hora de las decisiones de una comunidad de especialistas, en este caso, compuesta de historiadores. 
162 EL TALLER DE LA HISTORIA 2

Hemos tenido un problema serio de plazos, que vosotros habéis sufrido, en la organización de este II Congreso: ha habido que organizado todo en seis meses, por causas ajenas a nuestra voluntad. Es realmente un milagro que, en estas condiciones, hayamos podido obtener unos frutos para nosotros tan satisfactorios: os lo debemos a vosotros; algunos habéis tenido que renunciar a compromisos previos para poder asistir. Ante el poco plazo habido para organizar el congreso hemos acudido a Internet para acelerar el proceso de convocatoria, que por las vías tradicionales, para un evento de esta envergadura, nos habría llevado cuando menos dos años de preparación. De manera que los que estáis conectados a Internet, la práctica totalidad de ponentes y comunicantes, y una gran parte de los inscritos, habéis recibido el call for papers cinco meses antes que el resto. Hubo a colegas de lugares "lejanos" que les llegó incluso la convocatoria — por correo postal— después de haberse celebrado el congreso.

Decimos todo esto para dar un ejemplo próximo de cómo existen ya dos tipos de comunidades historiográficas, una con vocación más global y dinámica, conectada a Internet, y otra más localista y rutinaria, aún fuera de la $\operatorname{Red}^{102}$; la primera menos numerosa que la segunda pero más decisiva en cuanto a propuestas de futuro y debates de presente. Queremos decir que nuestra atención organizativa se ha concentrado en Internet ${ }^{103}$, no sólo por cuestiones coyunturales, también porque somos conscientes de que estamos ayudando a nacer una nueva comunidad de historiadores, verdaderamente global, una nueva forma de comunicación entre

102. Muchos colegas, al menos en España, tienen conexión y dirección electrónica asignadas por los servidores de sus universidades, pero no las utilizan, o lo hacen de una manera harto restringida; la generalización del comercio electrónico, las facilidades futuras para conectarse en el propio domicilio y el ascenso de la nueva generación, completarán sin duda el proceso de universalización de Internet y de la nueva historiografía.

103. Sin abandonar los métodos tradicionales, al menos de momento, a pesar de su coste y extrema lentitud: hemos distribuido más del doble de folletos (junto con la Encuesta) que convocatorias por correo electrónico, llegando por correo postal a más de 30.000 historiadores de 50 países. 
historiadores e historiografías que esperamos juegue un papel capital en el desenlace de la transición paradigmática al siglo XXI.

Dijimos que globalización y nuevas tecnologías hacen posible una historia más global en dos sentidos: permiten una historiografía más global-mundial, y crean condiciones técnicas para una aproximación más global-total a nuestros objetos. Porque los problemas habidos para llevar a la práctica el paradigma renovador de la historia total también se deben a los límites físicos del soporte utilizado para plasmar nuestras investigaciones: el libro con su número limitado de páginas y su modo de lectura lineal, con un único principio y final, y la sola potestad de unas breves citas en el texto o notas a pie de página. Sin embargo, la técnica del CD-ROM posibilita incluir, en la fase de investigación y/o en la fase de divulgación, además de textos escritos, la evidencia oral y visual del sonido y del vídeo, con lo cual nos acercamos a la percepción global de la realidad que nos permiten cotidianamente los cinco sentidos humanos ${ }^{104}$. Las fuentes se pueden de este modo diversificar, reproducir en su soporte original y combinar globalmente.

Pero es el hipertexto, que manejamos cotidianamente navegando por la Web, junto con los recursos multimedia, lo que puede transformar el proceso de investigación y el proceso de divulgación en un todo ${ }^{105}$, aproximando la práctica tradicionalmente analítica y fragmentadora de las ciencias sociales a una realidad que sabemos esencialmente sintética, compleja y global. Las citas y notas son ahora enlaces que nos trasladan a textos con la longitud que se deseen, dentro de los cuales podemos incluir asimismo otros vínculos que conduzcan a otros textos (sonidos o imágenes). Con lo cual la obra puede tener más de un principio y más de un final,

104. El conocimiento científico ha de imitar hoy al conocimiento común para seguir desarrollándose, desandando en parte el camino iniciado en el siglo XVII.

105. Una novedad metodológica porque los clásicos de las ciencias sociales han distinguido netamente entre método de investigación y método de exposición (Marx dixit). 
164 EL TALLER DE LA HISTORIA 2

además de una difusión en la red de redes virtualmente mayor que un libro.

Esta nueva técnica de hipertexto y multimedia, llamadas hipermedia, en formato CD-ROM o Internet, se está aplicando ya a la enseñanza y la divulgación de la historia, pero todavía no a la investigación, aunque existen experiencias pioneras en arqueología e historia del arte $^{106}$. La implantación de Internet en todos los niveles de la enseñanza beneficiará el cambio de mentalidades indispensable para universalizar a plazo medio el uso de las nuevas tecnologías, también en la investigación histórica, cuando sea pertinente, es decir, cuando precisemos aproximaciones globales cruzando textos, sonidos, imágenes y vídeos, lo cual dependerá de las fuentes disponibles y de nuestra capacidad intelectual para articular y sintetizar datos tan diversos.

\section{UNA HISTORIA MÁS REIVINDICATIVA}

$\mathrm{Y}$, terminando con nuestras propuestas, pensamos que es menester, en la tesitura actual, una historia que reivindique más su papel en la sociedad y la cultura, respecto de otras disciplinas y ciencias, de los poderes políticos y de los medios de comunicación social.

Se ha hecho ayer aquí la proposición de constituir, en España, un colegio profesional de historiadores-investigadores. Seguramente no es el mejor camino crear un "colegio" más con todas sus concomitancias corporativas, pero el vacío existe, y se está intentando llenar, en España, con el relanzamiento público de la más antigua corporación historiográfica, la Real Academia de la Historia.

106. Es el caso de la tesis doctoral de Antoni Mercader (Universitat Pompeu Fabra, Barcelona) sobre el arte conceptual 1963-1994 en formato CD-ROM (aunque por imperativo académico tuvo que presentar una copia en papel), donde se cruzan textos y análisis de términos con arte digital y vídeos, datos y sonidos con imágenes estáticas y móviles; véase www.upf.es/depeca/mercader.htm. 
Hay que reconocer que las asociaciones de historiadores existentes, según el catálogo de áreas de conocimiento académicamente vigentes, no sirven para defender públicamente los intereses de los historiadores y de la historia. Cumplen un papel posiblemente necesario hacia el interior de cada "gremio", y quienes las mantienen en funcionamiento tienen por ello nuestro reconocimiento, porque el tiempo que le dedican a esa labor se lo restan a otras tareas académicas seguramente más rentables y satisfactorias en lo personal. Pero hay que reconocer que dichas asociaciones no valen para conectar los historiadores con la sociedad, con los otros historiadores, con los órganos del poder académico, mediático y político. Durante el largo "debate de las humanidades" iniciado en 1997, ninguna de nuestras asociaciones especializadas ha intervenido como tal, ni tampoco en relación con el problema laboral de los jóvenes historiadores ${ }^{107}$. Los handicaps, difícilmente superables, son su composición excluyente de historiadores de otras áreas, la desconexión entre ellas y con la sociedad, en suma, una fuerte mentalidad corporativa pese a la independencia de estas asociaciones de toda institución académica o política concreta.

Necesitamos, pues, un nuevo asociacionismo historiográfico menos gremial y endogámico, que reivindique y comunique la historia con el mundo y a los historiadores entre sí — con independencia de si uno es medievalista, contemporaneista o historiador del derecho- alrededor de proyectos colectivos, dentro y fuera de la academia. Quizás en lo de "colectivos" esté el problema. La dificultad de los historiadores para organizarse, más allá de los marcos e intereses personales vinculados a la carrera académica, tiene que ver con la frecuentemente citada crisis de todo proyecto colectivo, no institucional, que Historia a Debate quiere desmentir en el campo historiográfico, animando a otros a seguir por el mismo camino, que habremos de convertir en la gran avenida por la que pueda transitar la historia futura.

107. "La historia que queremos", Revista de Historia "Jerónimo Zurita", No 71,1995, pp. 309-345. 
166 EL TALLER DE LA HISTORIA 2

Nada más, hacemos votos para el que "retomo al pasado" que estamos viviendo se convierte pronto en "retomo al futuro", sirviéndonos de las nuevas tecnologías y llevando con nosotros lo mejor del siglo XX.

Historia a Debate lucha por ello, que así sea y que lo podamos ver. Gracias. 